
\title{
$\begin{array}{ll}\text { Research Square } & \begin{array}{l}\text { Preprints are preliminary reports that have not undergone peer review. } \\ \text { They should not be considered conclusive, used to inform clinical practice, } \\ \text { or referenced by the media as validated information. }\end{array}\end{array}$
}

\section{Combat Process Simulation and Attrition Forecasting Based on System Dynamics and Multi-Agent Modeling}

BO PENG ( $\sim$ plapengbo@yeah.net)

Institute of health service and transfusion medicine, Academy of military medical sciences

Shuo Liu

AMMS

Lei Xu

AMMS

Zhen He

AMMS

\section{Research}

Keywords: Attrition forecast, Injury occurrence, System dynamics, Multi-agent, combat casualty

Posted Date: May 29th, 2020

DOl: https://doi.org/10.21203/rs.3.rs-30899/v1

License: (c) (i) This work is licensed under a Creative Commons Attribution 4.0 International License. Read Full License

Version of Record: A version of this preprint was published at Expert Systems with Applications on September 1st, 2021. See the published version at https://doi.org/10.1016/j.eswa.2021.115976. 


\section{Abstract}

Purpose: To predict and analyze the spatial and temporal distribution of combat attrition.

Methods: Construct a combat process simulation and combat attrition forecasting model using system dynamics methods and introduce macroscopic attrition data to the attrition forecast model by using agents to decompose the attrition data, assigning battle wound information according to specific ratios.

Results: Using the attrition forecast model, based on system dynamics, the causal loop and stock-flow relationship of the combat operation process may be constructed by combining the specific combat mission with an analysis of the factors that influence the operation, such as the lethality of the weapons and the defensive capability of the two sides. The damage levels of the various targets on the two sides in combat are converted into attrition data. Based on these data, an agent modeling method is used to extract the macroscopic attrition data derived from the battle attrition forecast model. By constructing a correspondence between the combat target damage level and the various types of battle injuries, the injury to each casualty may be modeled and assigned a value in order to complete the mapping from attrition to injury.

Conclusions: This work establishes an attrition forecasting model based on system dynamics and an agent-based simulation model for the occurrence of casualties. It can estimate the temporal and spatial distribution of attrition in combat.

\section{Introduction}

Attrition refers to the reduction in the effectiveness of a military force due to the loss of personnel and material ${ }^{110}$. In modern warfare, the lives of soldiers are particularly valuable and the ability to forecast attrition can provide a scientific basis for the development of logistical plans, helps to allocate logistical resources efficiently, improves the targeting and timeliness of logistics, and can save the lives of soldiers. The problem of predicting combat attrition is complex and nonlinear, has fuzzy characteristics, and is fraught with difficulties. Since WWII, the armed forces of all countries attach great importance to research into forecasting attrition. The main research methods include the following: First, there are statistical research methods, using regression analysis, ridge regression, principal components analysis, and other numerical approaches ${ }^{\llbracket 20304 \rrbracket}$. The United States began using multiple linear regression methods to measure the factors affecting combat casualties in the $1960 \mathrm{~s}^{\square 5}$. The relevant parameters were determined mainly by exercises and using historical data. Secondly, there are operational research methods, such as Lanchester equations, which provide a semi-empirical method that provides a linear model for the loss of combat forces of the two sides ${ }^{\square[}$. In addition, American military historian T. N. Dupuy proposed a quantified judgment method of analysis that uses a set of algebraic equations, combined with multi-factor correction values to predict the lethality of war in a regression method based on a large amount of historical data ${ }^{\square \square}$. Thirdly, there are computer simulation methods for forecasting attrition. Systems used internationally include the Patient Workload Generator (PATGEN) ${ }^{\square 8}$, the Small Patient Condition Stream Generator (SPCSG) ${ }^{\square 9}$, the Tactical Medical Logistics Planning Tool (TML+) ${ }^{\circledR 10 \rrbracket}$, the Joint Medical Analysis Tool (JMAT), and the Joint Medical Planning Tool (JMPT) ${ }^{0110}$. The Chinese military has also in recent years used medical service war game systems ${ }^{\square 12 \square}$ and medical support battlefield situational awareness systems ${ }^{13 \rrbracket}$ to simulate attrition.

The following problems exist in the current research. Conventional statistical methods for forecasting attrition based on historical combat data are inappropriate for predicting combat attrition when changes occur in the battle environment, combat mode, or weapons. Since combat action is an act of countermeasure filled with numerous stochastic factors, conventional operational research or combat simulation has ignored many of the non-quantifiable factors such as battle process and tactical variation. Furthermore, many of the parameters have fixed values and cannot be dynamically adjusted as the combat process changes. Current research methods for forecasting attrition can only predict static parameters such as the attrition rate and the casualty rate, but cannot make dynamic forecasts of the structural aspects of attrition such as the dynamic data for the temporal and spatial distributions of attrition. Neither can these methods analyze the microscopic information of attrition, such as specific injury information of wounded soldiers, nor can they help improve the accuracy of logistical resource data. ${ }^{[14015 \square}$

Here we solve the above problems through a combination of system dynamics (SD) and agent-based modeling and simulation (ABMS). System dynamics is primarily used in the analysis of information feedback systems and is an interdisciplinary science based on system recognition and solutions ${ }^{\square 16}$. The advantage of using system dynamics for combat process simulation and attrition forecasting is that, by simulating the feedback process, system dynamics can successfully reflect the interplay of the troop losses of both the red and blue forces. For example, the causality map can accurately describe the feedback relationships among the battle groups, battle modes, and combat environment; the flow diagram can effectively depict the consumption of forces on the red and blue sides; and the equations can provide an agile quantitative description of the local relationships between the elements of the battle systems. We set the simulation parameters according to the most recent modes of joint operation and the performance of modern weapons, and a system dynamics model is used to simulate the combat process and predict combat attrition by analyzing the damage to targets during a battle between red and blue forces. The central parameter, which represents the operational capability, can change automatically as the combat process proceeds. In addition, given the fact that system dynamics places the emphasis on the macroscopic analysis of the entire system, it is difficult to describe the individual entities in the system with microscopic detail. Through the use of an agent-based modeling and simulation (ABMS) method ${ }^{\square 17}$, we have organically integrated the microscopic behavior of members in the complex system with the attributes of the entire system. We decompose the macroscopic attrition forecast generated using the system dynamics model. We further analyze the microscopic injury information of each simulated casualty, such as the identity of the soldier, the affiliation of the troops, the time and location of injury, and death or injury conditions in order to quantify the temporal and spatial distribution of attrition, and to explore the main factors that affect the injuries in a land-based joint combat operation as well as the characteristics of combat wounds in order to provide a scientific basis for formulating a logistical plan.

\section{Methods}




\subsection{Establishing a attrition forecasting model based on system dynamics 2.1.1 Causality design of system dynamics}

This study was based on the background of the ground-air joint operation of conventional weapons under informationized conditions. The basic combat unit was a synthetic battalion and the basic combat mode was offense from a reinforced position. A basic logical countermeasure relationship between the red and blue forces was established using consultation from military experts ${ }^{\square 18}$. The causal relationship is shown in Fig. 1: (1) The blue force attacks $\rightarrow$ the defense of the red force is weakened $\rightarrow$ the red force suffers attrition $\rightarrow$ the offensive capability of the red force is reduced $\rightarrow$ the offensive demand on the blue force is reduced $\rightarrow$ the attrition rate of the blue force is reduced. (2) The red force attacks $\rightarrow$ the defense of the blue force is weakened $\rightarrow$ the blue force suffers attrition $\rightarrow$ the offensive capability of the blue force is reduced $\rightarrow$ the defensive demand on the red force is reduced $\rightarrow$ the attrition rate of the red force is reduced. (3) The blue force defends $\rightarrow$ blue resists the attack of red - the attrition rate of the blue force decreases $\rightarrow$ the decrease in blue force's attack capability slows down. (4) The red force defends $\rightarrow$ the red force resists the attack of the blue force $\rightarrow$ the attrition rate of the red force decreases $\rightarrow$ the decrease in the red force's attack capability slows down. (5) Factors that affect the attack and defense capabilities of both red and blue forces include: the climate, geographical environment, morale, and training.

\subsubsection{Design of stock-flow relationship in red and blue engagement}

The battle groups and engagement relationships were set up according to the actual combat between the red and blue forces. The red force had 7 combat groups including a ground assault group, an air combat group, an artillery group, an information warfare group, and a support and logistics group ,etc. The blue force had 5 combat groups: a left-flank defense group, a right-flank defense group, an artillery group, an air attack group, and an information warfare group $^{\square 19}$. A total of 39 sets of engagement relationships were formed between the red and blue forces to describe the dynamic changes from the loss of the combat groups to the attrition of troops and the analysis of downsizing. Here we only describe the simplest combat relationship between the red and blue forces as an example, as shown in Fig. 2.

Here RA and BA represent respectively a ground combat group of the red and blue forces. The stocks RF_RA and RF_BA represent the remaining elements of the red and blue forces while the stocks DF_RA and DF_BA represent the attrition of the two sides. The parameters IF_RA, Att_RA, and Def_RA represent respectively the initial strength, attack capability, and defensive capability of a combat group of the red force. The flows CR_RA and CR_BA represent the attrition rates of the two sides. Their calculation method is:

$$
\left\{\begin{array}{l}
C R \_R A=C A E_{-} B A t o R A \times E R E \_B A t o R A \times O C E \_B \times R F \_B A / I F \_B A \\
C R \_B A=C A E \_R A t o B A \times E R E \_R A t o B A \times O C E_{-} R \times R F_{-} R A / I F_{-} R A
\end{array}\right.
$$

Where the dynamic variables $C A E \_R A t o B A, E R E \_R A t o B A$, and $O C E \_R$ represent respectively the engagement rule setting equation, the operational influence factor quantification equation, and the equation for calculating the operational losses of a combat group designated RA in the red force and a combat group designated $\mathrm{BA}$ in the blue force.

\subsubsection{Calculation of engagement rule setting equation}

The rules of engagement may be subdivided into 3 categories: directly aimed weapons, long-range indirectly aimed weapons, and air strike weapons. This article focuses on the design of the rules of engagement for combat between red and blue forces using directly aimed weapons. Among them, the dynamic variables ERE_RAtoBA and ERE_BAtoRA are respectively the rules of engagement functions of a certain ground combat group of the red force against a certain combat group of the blue force, using directly aimed weapons. Figure 3 shows the stock-flow diagram of this type of function.

In Fig. 3, the parameters RA, RB, and RC represent three ground combat groups of the red force. Parameters BA and BB represent respectively two defense combat groups of the blue force. Stocks Distance_RA and Distance_BA represent the distances to the target from a detachment of the red force and a detachment of the blue force respectively. Stocks RF_BA and RF_BB represent respectively the remaining combat forces of the two combat groups BA and BB of the blue force. The dynamic variables Speed_RA and Speed_BA are real-time speeds, and parameters Range_RA and Range_BA are the effective ranges. The speed of the red combat group is affected by the distance between the red and blue groups as well as the range of the blue group. When the red group enters the range of the blue group, the blue group attacks targets in the red group with directly aimed weapons. This impedes the attack of the red group and slows it down. The blue group adjusts its speed according to its distance from the red group. When the red group is too close, the blue group retreats and puts up a multi-staged defense as it fights while retreating. The specific computation method for dynamic variables ERE_RAtoBA and ERE_BAtoRA of the rules of engagement between the combat groups of the red force and the blue force is:

$$
\begin{aligned}
& E R E \_R A t o B A=\left(\text { Distance_RA }- \text { Distance } \_B A\right)>\text { Range_RA } 0:\left(\text { Distance } R A-\text { Distance } \_B A\right) \leq y_{m} \\
& y_{m}=\frac{\text { Range_RA }}{x_{n}} \text { ? } 1: \frac{\text { Range_RA }}{x_{m}} /(\text { Distance_RA - Distance_BA }) \\
& E R E \_B A t o R A=(\text { Distance_RA }- \text { Distance_BA })>\text { Range_BA } ? 0:(\text { Distance } R A-\text { Distance_BA }) \leq y_{n} \\
& y_{n}=\frac{R a n g e_{-} B A}{x_{i}} ? 1-E R E_{-} B C t o R A:\left(1-E R E_{-} B C t o R A\right) \times \frac{\text { Range_BA }}{x_{j}} /(\text { Distance_RA }- \text { Distance_BA })
\end{aligned}
$$

\subsubsection{Calculation equations for quantifying combat influence factors}

This subsection describes the equations that are used for calculating the combat influence factors with the relationship between the stock and flow shown in

Loading [MathJax]/jax/output/CommonHTML/fonts/TeX/fontdata.js 
The dynamic variable calculation of the two combat influence factors OCE_R and OCE_B involves several parameters and dynamic variables. Among them, the parameters Training_R, Morale_R, Combat_mode, Topography, and Climate represent respectively the quantified values of the influence factors for training, morale, combat style, natural terrain, environment, and climate for both the red and blue forces. The parameters Logistical_R and Intelligence_R represent respectively the quantified values of logistical support capabilities and information support operations capabilities. The stocks $\mathrm{RE}$, $\mathrm{BE}$, RF, and $\mathrm{BF}$ are respectively the current capability of the support forces and information operations forces of the red and blue sides. The specific calculation method is as follows:

$$
\left\{\begin{array}{c}
\text { OCE_R }=\left(\text { Logistical_R } \times x_{1}+\text { Intelligence_R } \times x_{2}+\text { Training_R } \times x_{3}+\text { Morale_R } \times x_{4}\right) \times \\
\text { Combat_mode } \times \text { Topography } \times \text { Climate } \\
\text { OCE_B }=\left(\text { Logistical_B } \times x_{5}+\text { Intelligence_B } \times x_{6}+\text { Training_B } \times x_{7}+\text { Morale_B } \times x_{8}\right) \times \\
\text { Combat_mode } \times \text { Topography } \times \text { Climate }
\end{array}\right.
$$

Military experts were invited to perform a hierarchical analysis of the specific quantification methods for these combat influence factors. Then, based on the importance of the relationship between the four influence factors of morale, training, intelligence reconnaissance, and logistics support, the relationships were divided into five levels: critical, highly important, important, less important, and unimportant, and entered into their corresponding table in the matrix. ${ }^{\square 20} \mathrm{~A}$ comprehensive judgment matrix was then obtained by calculating the weighted geometric mean of the scoring matrix by all the military experts. The data were then arranged to produce a weighting for the four above-mentioned combat capability influence factors. After that, combat style was used as the dependent variable, while natural terrain and climate were used as independent variables. The results of the above calculation were entered in the combat influence factor quantification subsystem. In the process, expert advice was used to quantify the favorable or adverse effects of natural terrain and climate on the combat process under different combat conditions.

\subsubsection{Calculation equation for operational losses}

The Lanchester equations are a set of differential equations that describes the troop loss of 2 warring parties and can be used to make various predictions of the combat process. The equations comprise a deterministic model that does not require multiple iterations and is suitable for combat simulations of all sizes ${ }^{210}$. The internationally recognized Lanchester's second linear law is used to calculate the dynamic variables of combat losses including CAE_RAtoBA and CAE_BAtoRA. The algorithm is:

$$
\left\{\begin{array}{c}
C A E_{-} R A \text { to } B A=\frac{-x_{0}(k-1)}{e^{-a y_{0}{ }^{(k-1) t}-k}} \\
C A E_{-} \text {BAtoRA }=\frac{-y_{0}(k-1) e^{-a y_{0}(k-1) t}}{e^{-a y_{0}(k-1) t}-k}
\end{array}\right.
$$

Here $k$ is the ratio of the combat effectiveness of the red force to the blue force, $R x t i$ and $B x t i$ are respectively the current number of forces in a specific group of the red and blue forces at time $t ;$, att_Rx is the initial value of the offensive capability of the group in the red force, def_Bx is the initial value of the defensive capability of the group in the blue force; $k$ is calculated as follows:

$$
\mathrm{k}=\frac{\beta \times R F_{-} R x \times A t t \_R x}{\alpha \times R F_{-} B x \times D e f \_B x}
$$

An index model is established to calculate the initial values for att_Rx and def_Bx of the offensive and defensive capabilities of a specific group of the red and blue forces. The calculation is conducted in three steps: (1) Parameterization of weapon performance. Five parameters were chosen from previous literature to describe the offensive capability: attack distance, attack frequency, piercing depth, kill-radius, and hit accuracy ${ }^{\square 22 \square}$. Five parameters were chosen for defensive capability: armor thickness, camouflage, active defense, profile dimension, and maneuverability ${ }^{\square 23}$, also from previous literature. (2) Indexed parameters. The parameters for each weapon must be calibrated according to the same standard to ensure that the offensive and defensive capabilities of different weapons are comparable. (3) Index normalization. Indicators that quantify the characteristics of each weapon must be combined into a basic index by drawing radar charts and calculating the relevant areas. After calculating the indices of all single pieces of equipment, a weighted sum is obtained according to the number of weapons and the number of combat forces in each combat group to obtain the overall combat effectiveness of each combat group of the red and blue forces, which are then brought into the model for further processing.

Attrition forecasts made using Lanchester equations alone are known to have some limitations, such as modeling the combat operation as a deterministic process without considering any dynamic change in the attrition coefficients, the suppressive effect of weapons, terrain effects, and the spatial distribution of forces $^{\mathrm{D24}}$. Also, no considerations are given to morale, training, and other human factors. In this study, the basic Lanchester equations are treated as dynamic variables into which we introduce the system dynamics model. The loss of weapons and troop attrition occur in real time, the attrition coefficient changes with the simulation process as the related stock changes. This effectively solves the problem that the attrition coefficient does not change when the Lancaster equation alone is used for calculating attrition. In addition, this study also introduces other factors into the model, including the cooperation between combat groups, the rules of engagement of each group, and factors such as morale, training, terrain, and climate, in order to address the shortcomings of the original Lanchester equation.

Loading [MathJax]/jax/output/CommonHTML/fonts/TeX/fontdata.js 


\subsection{Simulation and forecast of wounded based on multi-agent modeling}

The system dynamics model addresses the problem of quantifying the temporal and spatial distribution of attrition in combat. The multi-agent model then analyzes the specific injuries of individual casualties based on the prediction of attrition.

\subsubsection{Structure of a single agent}

A single agent is used to reflect a specific type of wound structure. Here we use the weapon type as the independent variable and the target type as the dependent variable. Based on the data of a weapon attack animal injury model ${ }^{\square 25}$, we constructed a battle injury database and a battle injury spectrum, screened and summarized nine distinct categories of combat wound occurrence probability caused by three types of weapon: directly aimed weapons, longrange indirectly aimed weapons, and air strike weapons against targets with a high-, medium-, and low-level of protection. The probability of each type of combat injury includes nine specific data items: mortality rate, injury level, injury cause, injury type, injury site, multiple injuries, combined injuries, and

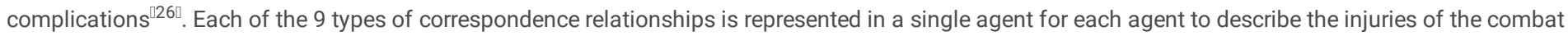
group caused by the attack of different weapons. The wounds are simulated in accordance with the logical sequence shown in Fig. 5 :

(1) Killed in action assessment. Determine whether or not the individual is killed in action or wounded.

(2) Assignment of injury cause. When the individual is not fatally injured, assign a value for the cause of injury by calling the correlation function and randomly assign a cause of injury to the individual according to the probability of different injury causes under the specific conditions using the combat injury database.

(3) Assignment of injury type. After determining the cause of the injury, assign the injury type information to the injured individual according to the probability of occurrence of different injury types under the specific conditions.

(4) Assignment of injury site. First, determine the number of injury sites for the injured individual according to the battle injury database and battle injury spectrum for the probability of different numbers of injury sites. Then, assign one or more injury sites to the injured individual based on the determined number of injury sites.

(5) Assignment of complication information. Determine the number of complications to randomly assign one or more specific complications.

(6) Assignment of injury level. First, determine the number of injury sites of the injured individual. The level of injury (minor, medium, heavy, and critical) is then determined according to the number of the injury sites. Then randomly assign an injury level to the injured individual according to the number of injury sites.

\subsubsection{Construction of the multi-agent group}

A multi-agent group is used to generate a batch of wounded under a specific type of wound structure. In the model, a number of multi-agent groups are constructed to represent the attrition caused by the attack of different combat groups of the blue force against the red force. To simplify the description, we use the attack of the blue force against only one combat group in the red force as an example, as shown in Fig. 6.

The three stocks in Fig. 6 represent respectively the attrition flows of a combat group of the red force after the attack by directly-aimed weapons, indirectlyaimed artillery, and air strikes of the blue force. Since the data needed for wound simulation should be in the form of discrete integers, an event must be constructed to transform the values. This event must contain a counting function and a trigger to execute the function at a specific time to monitor the attrition in real time. When the attrition of the monitored stock is greater than the number of multi-agents representing the number of wounded in the multiagent group, an accumulation cycle is performed until the number of multi-agents representing the wounded exceeds the attrition, then the accumulation is stopped. At this point, the macro-attrition data stream is discretized to represent a specific number of casualties in the multi-agent group. Then each agent can be assigned its injury information and distribution of the wounded can be displayed online using mapping software such as Google Maps (Fig. 7). The black dots in the figure indicate personnel of the red force killed in action, while red dots indicate injured personnel. Clicking on each red dot reveals specific injury information in the injured personnel table below the boundary.

\section{Results}

\subsection{Overall forecast of combat process and attrition}

According to the simulation results, the entire battle lasted $2 \mathrm{~h} 35 \mathrm{~min}$, and the red force achieved its expected goal. The total attrition and the rate of attrition are shown in Fig. 8. At the beginning of the battle, the artillery and air strike forces of both sides were focused on the force build-up area of the opposing side, which led to a large number of casualties in the early stages. The first peak in attrition occurred when the red force broke through the first line of defense of the blue side, forcing the ground forces of the two teams to engage. The second peak of attrition occurred during the red force's advance from the front line to the reserve position. The third wave of attrition occurred when the red force broke through the blue force's reserve position. At 65 minutes after the battle began, the blue polyline, indicating the attrition rate, exceeded the red polyline when the reserve of the red force joined the battle, causing the blue side's defensive forces to be largely eliminated, and the attrition rate of the blue force exceeded that of the red force.

The red force's total combat attrition was $15.91 \%$. The level of attrition for specific combat groups was $23.15 \%$ for the first batch of the main attack group, $23.9 \%$ for the assist attack group, $24.91 \%$ for the second batch, $22.62 \%$ for the information warfare group, $6.43 \%$ for the artillery group, and $1.11 \%$ for the

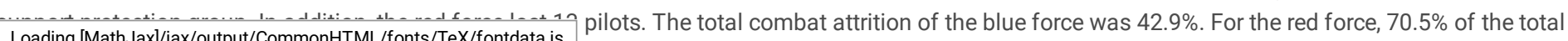


attrition belonged to its three ground assault groups. Although the information warfare group was behind the battlefield and did not directly face the enemy, its combat attrition accounted for $15.1 \%$ of the total. In the total attrition of the red force, $30 \%$ of the attrition was caused by directly-aimed weapons, $16 \%$ was caused by indirectly-aimed artillery, and $54 \%$ was caused by air strikes

\subsection{Casualty forecast}

We have analyzed the personnel injuries of the simulated battle according to injury severity, cause of injury, injury type, and injury site, and at the same time

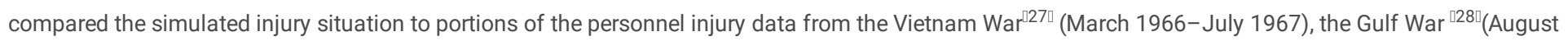
1990-February 1991), the Serbian Offensive in Eastern Slavonia ${ }^{\square 29}$ (September 1991-July 1992), the First Chechen War(December 1994-August 1996), the Second Chechen War ${ }^{130}$ (August 1999-May 2000), and the Operation Iraqi Freedom ${ }^{\natural 31 \square}$ (September 2004-September 2005). Through chi-square analysis, we summarized the characteristics of modern combat warfare ${ }^{\square 2 \square}$. The injury data of the above 6 wars were all from publicly available literature. Due to limited data, it cannot be guaranteed that the numbers of injured personnel were the same when the simulated data were compared to those of the 3 previous wars according to injury severity, cause of injury, injury type, and injury site. Moreover, the number of casualties in the statistics also differed from the total number of injured personnel in the previous wars.

\subsubsection{Injury prediction}

For the red force, the number of troops killed in the battle amounted to $27.1 \%$ of the total attrition. Among the casualties, $23.7 \%$ of the total number of injured individuals were critically injured or severely injured, $37 \%$ were moderately injured, and $39.2 \%$ had minor injuries. The injury distribution situation of the simulation was compared to the combat data from the Gulf War, the First Chechen War, and the Second Chechen War (Table 1). The overall trend exhibited a drop in the percentage of minor injuries and an increase in the percentage of severe injuries.

Table 1

Comparison of injuries between simulation results and actual combat data

\begin{tabular}{|c|c|c|c|c|c|c|c|c|c|c|c|}
\hline \multirow{2}{*}{$\begin{array}{l}\text { Injury } \\
\text { level }\end{array}$} & \multicolumn{2}{|c|}{ Simulation system } & \multicolumn{3}{|l|}{ Gulf War } & \multicolumn{3}{|c|}{ First Chechen War } & \multicolumn{3}{|c|}{ Second Chechen War } \\
\hline & Number & \%Percentage & Number & \%Percentage & Significance & Number & \%Percentage & Significance & Number & \%Percentage & s \\
\hline $\begin{array}{l}\text { Minor } \\
\text { injuries }\end{array}$ & 180 & 39.2 & 73 & 67.6 & $Y_{e s},<0.01$ & 3975 & 49.4 & Yes, $<0.01$ & 797 & 40.5 & $\Lambda$ \\
\hline $\begin{array}{l}\text { Moderate } \\
\text { injuries }\end{array}$ & 170 & 37.0 & 17 & 15.7 & $Y_{e s},<0.01$ & 2407 & 29.9 & $Y_{e s},<0.01$ & 655 & 33.3 & $\Lambda$ \\
\hline $\begin{array}{l}\text { Severe } \\
\text { and } \\
\text { critical } \\
\text { injuries }\end{array}$ & 109 & 23.7 & 18 & 16.7 & No,0.11 & 1665 & 20.7 & No,0.12 & 515 & 26.2 & $\Lambda$ \\
\hline
\end{tabular}

The distribution of injuries in each combat group is shown in Fig. 9. One notable feature is that the fraction of minor injuries decreased while the fraction of severe injuries and critical injuries increased. In particular, more than $50 \%$ of the casualties were in the artillery group and the logistical group. In addition, once an aircraft performing air strike missions was hit, more than $50 \%$ of the aircrew died. Most of the parachuted aircrew were severely or critically injured, posing new challenges for search and rescue missions.

\subsubsection{Prediction of injury causes}

Through simulation, we obtained the distribution of the cause of injury for this operation and compared it with relevant data from the Vietnam War, the First Chechen War, and the Second Chechen War (Table 2). The simulation predicted that $25.1 \%$ of the injury-caused attrition of the red force was due to blast injuries, while impact wounds and burn wounds accounted for $35.5 \%$ and $10.2 \%$ respectively, both of which were higher than those seen in previous combat statistics, and all 3 combining for a total of $70.8 \%$. In this situation, the number of injuries due to gunshot wounds and blade injuries that occurred frequently in traditional battles has decreased, indicating that the role of light weapons is less than in the past. In addition, the number of combined injuries, including fragment impact, and burn-blast injury has increased and accounted for $25.1 \%$ of the total. The increase in the number of individuals suffering combined injuries poses a severe challenge to the rescue of wounded. 
Table 2

Comparison of injury causes between simulation results and actual combat data

\begin{tabular}{|c|c|c|c|c|c|c|c|c|c|c|}
\hline \multirow{2}{*}{$\begin{array}{l}\text { Cause of } \\
\text { injury }\end{array}$} & \multicolumn{2}{|c|}{ Simulation system } & \multicolumn{3}{|c|}{ Vietnam War } & \multicolumn{3}{|c|}{ First Chechen War } & \multicolumn{2}{|c|}{ Operation Iraqi Freedom } \\
\hline & Number & \%Percentage & Number & \%Percentage & Significance & Number & \%Percentage & Significance & Number & \%Percentage \\
\hline $\begin{array}{l}\text { Gunshot } \\
\text { wounds } \\
\text { and blade } \\
\text { injuries }\end{array}$ & 19 & 4.1 & 4565 & 32.0 & $Y_{e s}<0.01$ & 4266 & 26.5 & Yes, $<0.01$ & 202 & 24.1 \\
\hline $\begin{array}{l}\text { Blast } \\
\text { injuries }\end{array}$ & 115 & 25.1 & 8485 & 59.4 & $Y_{e s},<0.01$ & 9482 & 58.9 & $Y_{e s},<0.01$ & 489 & 58.4 \\
\hline $\begin{array}{l}\text { Burn } \\
\text { wounds }\end{array}$ & 47 & 10.2 & 200 & 1.4 & $Y_{e s},<0.01$ & 885 & 5.5 & $Y_{e s},<0.01$ & 25 & 3.0 \\
\hline $\begin{array}{l}\text { Impact } \\
\text { wounds }\end{array}$ & 163 & 35.5 & 534 & 3.7 & $Y_{e s},<0.01$ & 1078 & 6.7 & Yes, $<0.01$ & 96 & 11.5 \\
\hline $\begin{array}{l}\text { Combined } \\
\text { injuries }\end{array}$ & 115 & 25.1 & 500 & 3.5 & $Y_{e s},<0.01$ & 386 & 2.4 & $Y_{e s},<0.01$ & 26 & 3.1 \\
\hline
\end{tabular}

In the distribution of the specific cause of injury in each of the combat groups of the red force, all the gunshot wounds and blade injuries occurred in the ground assault cluster, but the overall frequency of occurrence of gunshot wounds and blade injuries was generally low indicating that, in actual combat, due to the long range and high accuracy of new directly-aimed weapons, light weapons have only a limited role. Therefore, the main threat faced by troops performing ground combat tasks is still from the enemy's long-range directly-aimed weapons such as artillery and anti-tank missiles. The artillery group and the logistical group do not participate in frontal offensive operations, but they are key targets for the enemy's long-range firepower and air strikes, so the injuries suffered by these two groups were mostly impact wounds, burns, and combined injuries caused by explosions.

\subsubsection{Prediction of injury types}

For the distribution of injury types in the red force, $30.7 \%$ of the total were penetration wounds, $19.0 \%$ were fractures, dislocations, or broken limbs, and $18.5 \%$ were contusions and soft tissue injuries. These were the top 3 injury types. According to our analysis, this was due to the high proportion of artillery and air strikes in modern warfare, in which explosion fragments cause a large number of penetrating wounds. Further, explosions in confined environments such as vehicle cabins can easily cause internal organ contusion and limb fractures. In addition, due to the reduced number of bullet wound injuries, penetrating wounds, and cut wounds caused by bullets, accounted for only $7 \%$ and $3 \%$ of all injury types respectively, which is significantly lower than in historical data (Table 3).

Table 3

Comparison of injury types between simulation results and actual combat data

\begin{tabular}{|c|c|c|c|c|c|c|c|c|c|c|}
\hline \multirow[t]{2}{*}{ Injury type } & \multicolumn{2}{|c|}{ Simulation system } & \multicolumn{3}{|c|}{ Vietnam War } & \multicolumn{3}{|c|}{ Serbian Offensive in Eastern Slavonia } & \multicolumn{2}{|c|}{ Operation Iraqi Freedom } \\
\hline & Number & \%Percentage & Number & \%Percentage & Significance & Number & \%Percentage & Significance & Number & \%Percentage \\
\hline $\begin{array}{l}\text { Fractures, } \\
\text { dislocations, } \\
\text { or broken } \\
\text { limbs }\end{array}$ & 87 & 19.0 & 7537 & 14.9 & No,0.02 & 330 & 27.3 & Yes, $<0.01$ & 154 & 15.6 \\
\hline $\begin{array}{l}\text { Contusions } \\
\text { and soft } \\
\text { tissue } \\
\text { injuries }\end{array}$ & 85 & 18.5 & 2495 & 4.9 & Yes, $<0.01$ & 205 & 16.9 & No,0.44 & 62 & 6.3 \\
\hline $\begin{array}{l}\text { Penetration } \\
\text { wounds }\end{array}$ & 141 & 30.7 & 14137 & 28.0 & No,0.19 & 217 & 17.9 & Yes, $<0.01$ & 223 & 22.6 \\
\hline $\begin{array}{l}\text { Blind tracks, } \\
\text { cuts, and } \\
\text { penetration } \\
\text { wounds }\end{array}$ & 48 & 10.5 & 24169 & 47.8 & Yes, $<0.01$ & 318 & 26.3 & Yes, $<0.01$ & 489 & 49.6 \\
\hline $\begin{array}{l}\text { Blood } \\
\text { vessels, } \\
\text { nerves, and } \\
\text { other } \\
\text { injuries }\end{array}$ & 98 & 21.4 & 2235 & 4.4 & Yes, $<0.01$ & 141 & 11.6 & Yes, $<0.01$ & 57 & 5.8 \\
\hline
\end{tabular}

In terms of the specific injury type distribution of the combat groups in the red force, the ground assault cluster not only faced the assault of directly-aimed weapons by the ground defense of the blue force, but also the attack of indirectly-aimed weapons and air strikes of the blue force. As a result, this cluster suffered penetrating wounds, contusions, fractures caused by explosions, and other types of injuries to the skin and soft tissue due to burns, as well as penetrating injuries, blind track injuries, and tangential injuries that are mainly caused by bullets from light weapons. This complexity of types of injury poses a challenge for the rescue of the wounded on the battlefield. Although the artillery group and the logistical group are concentrated behind the battlefield, they still face the threat of long-range enemy fire. Their injury types are mainly penetrating wounds, contusions, skin and soft tissue injuries, and fractures.

\subsubsection{Prediction of iniurv sites}


Among the injured of the red force, head, face, and neck injuries accounted for $18.7 \%$ of the total number of wounded, and the proportion of upper limb injuries was $17.9 \%$. These statistics are relatively close to the relevant previous data. Chest and back injuries accounted for $24.6 \%$ of the total number of wounded, while abdominal (waist) injuries accounted for $15.9 \%$, higher than that in the historical data. Analysis showed that this was mainly because most of the weapons used in combat were vehicle-borne, and most of the combat personnel were in the cabins of armored vehicles. As the trunk of the body has a greater surface area than that of the limbs, this makes chest and back injuries more likely in this situation. The proportion of lower limb injuries was $22.9 \%$, lower than that in the historical data. Analysis revealed that, given the fact that modern troops are basically vehicle-mounted, the chances of infantry leaving the vehicle to fight is reduced, thus resulting in a decrease in the proportion of lower limb injuries (Table 4).

Table 4

Comparison of injury sites between simulation results and actual combat data

\begin{tabular}{|c|c|c|c|c|c|c|c|c|c|c|c|}
\hline \multirow[t]{2}{*}{ Injury site } & \multicolumn{2}{|c|}{ Simulation system } & \multicolumn{3}{|c|}{ Vietnam War } & \multicolumn{3}{|c|}{ First Chechen War } & \multicolumn{3}{|c|}{ Operation Iraqi Freedom } \\
\hline & Number & \%Percentage & Number & \%Percentage & Significance & Number & \%Percentage & Significance & Number & \%Percentage & : \\
\hline $\begin{array}{l}\text { Head, } \\
\text { face, and } \\
\text { neck }\end{array}$ & 86 & 18.7 & 4180 & 15.7 & No,0.07 & 5715 & 35.5 & Yes, $<0.01$ & 203 & 21.7 & 1 \\
\hline $\begin{array}{l}\text { Chest and } \\
\text { back }\end{array}$ & 113 & 24.6 & 3490 & 13.1 & Yes, $<0.01$ & 1384 & 8.6 & Yes, $<0.01$ & 127 & 13.6 & ' \\
\hline $\begin{array}{l}\text { Abdomen, } \\
\text { waist, } \\
\text { pelvis, } \\
\text { and } \\
\text { perineum }\end{array}$ & 73 & 15.9 & 3048 & 11.4 & Yes,,$<0.01$ & 1288 & 8.0 & Yes,$<0.01$ & 141 & 15.1 & 1 \\
\hline $\begin{array}{l}\text { Upper } \\
\text { limbs }\end{array}$ & 82 & 17.9 & 7106 & 26.7 & Yes, $<0.01$ & 3155 & 19.6 & No,0.36 & 157 & 16.8 & I \\
\hline $\begin{array}{l}\text { Lower } \\
\text { limbs }\end{array}$ & 105 & 22.9 & 8838 & 33.1 & Yes,$<0.01$ & 4555 & 28.3 & Yes, 0.01 & 307 & 32.8 & , \\
\hline
\end{tabular}

Of all the combat injury attritions in the red force, 302 individuals had single wounds, 157 were wounded at 2 body sites, and 45 were wounded at 3 or more sites. The percentage of multiple injuries was $34.2 \%$, much higher than the $9.5 \%$ in the Russo-Georgian War and the $18 \%$ in the Gulf War. Figure 10 shows the distribution in the number of injury sites for the various combat groups of the red force. The percentage of multiple injuries is $29 \%$ for ground assault clusters, $31.3 \%$ for artillery groups, and $57.5 \%$ for logistical groups. As the ground assault sections of the red force are equipped with armored vehicles and the level of personnel protection is high, the number of multiple injuries is low. Although the artillery group and the logistical group are behind the frontline, they lack armor protection and their personal protective equipment is also weak, so their risk of multiple injuries is high.

\section{Conclusions}

Through simulations of this combat mode and comparative analysis with previous combat data, the results were found to be highly consistent and reflect the nature of attrition in a modern war as compared to traditional combat. Notable points include: (1) The fraction of severe injuries and critical injuries has increased and the fraction of minor injuries has decreased; (2) The percentage of combined injuries and multiple injuries is significantly higher than that in previous operations; (3) The fraction of explosion injuries and impact wounds, as well as burn injuries caused by explosion has increased. Fragments from explosions produce extensive penetrating wounds while shock waves generated by explosions have led to an increase in the percentage of internal organ wounds and facial wounds of periosteum, nasal cavity, and eyes. In contrast, traditional gunshot wounds and blade injuries are significantly reduced; (4) The number of patients with combined injuries and multiple injuries has increased. Such injuries are severe, can deteriorate rapidly, have high mortality and risk of shock, and can easily be missed. Therefore, they call for much increased attention during the treatment of battle injuries.

\section{Discussion}

This study has applied system dynamics to the prediction of attrition. The advantage of this method is that the main elements of system dynamics are well suited for describing the various elements of the battle. The feedback relationship can effectively reflect the interplay between the attrition of the red and blue forces during the battle. In addition, the use of multi-agent simulation for detailed modeling of the wounded can alleviate the shortcomings of system dynamics in that it focuses mainly on the macroscopic analysis of the entire system and not on the detailed microscopic description of specific individuals. Therefore, this study has not only improved the accuracy and correctness of attrition forecasting, but also further expanded the contents of attrition research, and made an in-depth investigation of the temporal and spatial distribution of the specific injury structure of the wounded. The results may be used to provide accurate, efficient, and comprehensive estimates of attrition and casualties in combat, and also be used to provide a scientific basis for formulating a logistical plan, for mobilizing health workers and material resources, and for rationally allocating health resources in the effective implementation of battle injury treatment ${ }^{\natural 3}$. There are still some deficiencies in this study. (1) At present, it is only possible to carry out more precise downsizing predictions for a specific battle, and it is difficult to apply the predictions to battles lasting more than 1 day and wars of longer duration; (2) the attrition reduction used in this study is expected to be difficult to apply to other combat styles such as cross-sea landing operations and modern naval warfare; and (3) the probabilities of the war injuries used in the simulation of the wounded in this study were mainly derived from experimental data on the effects of weapons on animals, and although this is the closest to the capabilities of modern weapons to cause injury, there is a large difference between the simulated injuries and the combat injuries of combatants in actual operations. These problems will be solved as the research of relevant subject matter progresses. 


\section{Declarations}

\section{Ethical Approval and Consent to participate}

Not applicable

\section{Consent for publication}

Not applicable

\section{Availability of data and materials}

All the data involved in this paper are annotated in the references.

\section{Competing interests}

The authors declare that they have no competing interests.

\section{Funding}

Major Research Project of Chinese PLA Military Logistics (BWS14J04,AWS15J004,BWS14J041,

\section{Authors' contributions}

Bo Peng wrote the article, and Zhen He and Lei Xu provided the idea. Shuo Liu investigated the Haddon matrix and screened and analyzed the data. All authors haveread and approved the final manuscript.

\section{Acknowledgements}

Not applicable

\section{References}

1. Institute of Health Service and Medical Information; Academy of Military Medical Sciences; Reduction classification and algorithm $\llbracket \mathrm{GJB} 7479-2012[S]$. Beijing $\otimes T$ The General Logistics Department of PLA囚2012ه5

2. Zhang lulu. Military health service [M]. Shanghai: The second military medical university press,2017:36-40

3. Xu lei. Research on multi-factor analysis and prediction method of combat attrition rate [D]. Xi 'an: department of preventive medicine, the fourth military medical university, 1996

4. Wojcik,B, Stein,C. The Challenge of Mapping between Two Medical Coding. Systems[J]. Mil Med, 2006,171(11):1128.

5. Feng zhiguang, et al. The latest U.S. army weapon systems [M]. Beijing: aviation industry press, 2012:225-300

6. Zhong yongguang. System dynamics [M]. Beijing: Science press,2012:15-20.

7. LI Li-juan囚DIAO Tian-xi. Development and implementation of the U. S. military joint theater trauma system [J]. Mil Med Sci,2012,36(9):158-160.

8. Barbara E. Wojcik, Rebecca J. Humphrey, LTC Lawrence V, et al. Comparison of Operation Iraqi Freedom and Patient Workload Generator Injury Distributions[J]. MILITARY MEDICINE, 2008,173,(7):647.

9. Wesley Sherman, Gerry Pang. Small Patient Condition Stream Generator(SPCSG): Version 2.0 [M]. Naval Health Research Center.

10. ZHANG Yin囚MENG Hai-bin囚DIAO Tian-xi. A Tactical medical logistics planning. tool: analysis and inspiration [J]. Mil Med Sci,2012,36(12):350-353

11. James M. Zouris G . Jay Walker. Scenario-Based Projections of Wounded-in-Action Patient Condition Code Distributions[M]. Naval Health Research Center

12. PENG Bo, ZHANG Wen-qin, DU Guo-fu , et al. A simulation research on casualty. prediction based on system dynamics and agent-based modeling [J]. Academic Journal of Second Military Medical University, 2008,39 (5) :510-513

13. Tan Bin,WANG Yun-dou. Application of neural network to forecasting the loss due to noneffective, 2004,12:17-18

14. PENG Bo,Xu yugu. Research status and trend of modern warfare conventional. weapon casualty generation simulation[J]. Journal of the PLA health service $₫ 2015 \rrbracket 17 \rrbracket 3 \otimes \square 899-592$.

15. DENG Yue-xian ,QIN Chao, LIRui-xing, et al. Monte Carlo Simulation in risk analysis of battle casualty forecasting in urban aggressive military action [J]. Academic Journal of Second Millitary Medical University,2008,29(7):826

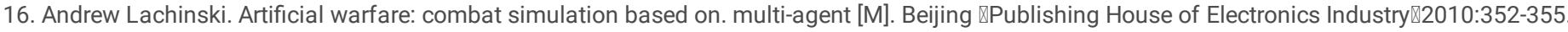

17 Than lina Mathematical mndelina and mathematical experiments [M]. Beijing: Higher Education Press, 2000:110-120.

Loading [MathJax]/jax/output/CommonHTML/fonts/TeX/fontdata.js 
18. Peng Bo, Guo Yuanhui, Xu Lei, he Zhen. Simulation and data analysis of attrition in land joint operations [J]. Military medicine, 2019,43 (08): $564-569$

19. Zhang mingshuang, Xu kehu, Li Lingzhi. Target threat assessment index system of synthetic brigade [J]. Fire and Command Control, 2019,44 (12): 108113

20. PENG Bo,Kuai liping,Zhang liqian, et al. The questionnaire consultation and analysis of the war wound spectrum of conventional weapons based on graded treatment [J]. Peole's Military Surgeon, 2008, 61 (10):895-897.

21. Luo Xiaoming. Mathematical Modeling and Simulation Analysis of Asymmetric Warfare [M].Beijing区National Defense Industry Press:94-95

22. ZHAO Ding-hai, et al. A Kind of Common Index Model of Weapon's Attack. Capability [J]. Journal of Academy of Armored Force Engineering, 2015,29 (5):10-13

23. QIN Chao, CHEN Guo-liang, LI Rui-xing, et al. A Forecasting Model of Army Corps Casualty Rate in Mountain Offensive Operations [J]. Chinese Journal of Management Science,2004,12(4):125

24. Wang Jiusheng, Qin Chao. Quantitative Study On the Main Influencing Factors of Combat Attrition [J]. Southeast National Defense Medicine, 2004,6(5): 387

25. Qidan, Chengtao, et al. Research on Shipborne Artillery Weapon System Based on Multi-agent Theory[J]. Journal of System Simulation,2006,18(7): 20172021.

26. Wang Zhengguo. Field Surgery[M]. People's Medical Publishing House囚2010囚117-118

27. Rober M. Viet Nam Wound Analysis[J].The Journal of Trauma.1978囚18(9):635

28. Matthew S.Goldberg. Death and Injury Rates of U.S. Military Personnel in Iraq[J].MILITARY MEDLINE,2010,175(4):220

29. Durda Sebalj, et al. Surgical Treatment of 1,211 Patients at the Vinkovci General Hospital, Vinkovci, Croatia, during the 1991-1992 Serbian Offensive in East Slavonia[J]. MILITARY MEDICINE, 1999,164(11):803.

30. Корнюшко,И.Г.,Бояринцев,В.В..Организация медицинского обеспечения войск в ходе операции по принуждению Грузии к миру[Ј]. Военномедицинский журнал, 2009,02:4.

31. Amber L.Dougherty, Charlene R.Mohrle, Michael R.Galarneau, et al.Battlefield extremity injuries in Operation Iraqi Freedom[J].Injury,2009:772-777.

32. Zhang mingzhi. Military quantitative analysis method [M]. Beijing: National. defence of Industry Press, 2015:175-180.

33. Li Fusheng, Zhang Sizhong, Fu Wei. Analysis and prediction of health attrition in conventional weapons war [J]. People's Military Surgeon, 1980 (07): 2123

\section{Figures}

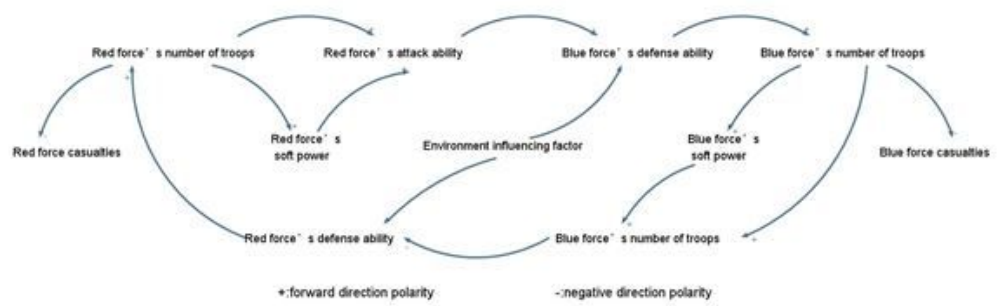

Figure 1

Causal circuit diagram of the red-blue engagement process

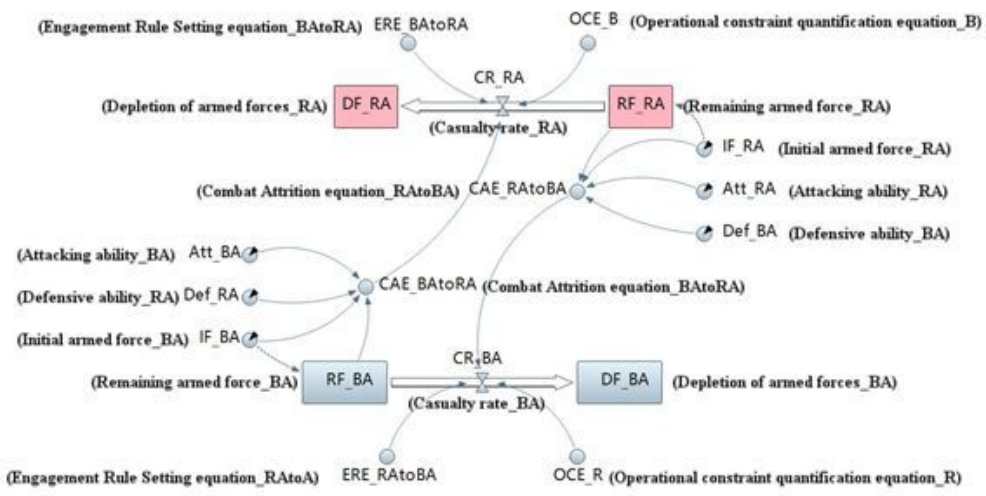

Figure 2 
Stock-flow diagram of red-blue engagement (partial) RA: the ground combat group of the red force; BA: the ground combat group of the blue force; RF_RA: the remaining elements of the red force; RF_BA: a remaining elements of the blue force; DF_RA: the attrition of the red force; DF_BA: the attrition of the blue force; IF_RA: the initial strength of the red force; Att_RA: the attack capability of the red force; Def_RA: the defensive capability of the red force; CR_RA: the attrition rates of the red force; CR_BA: the attrition rates of the blue force.

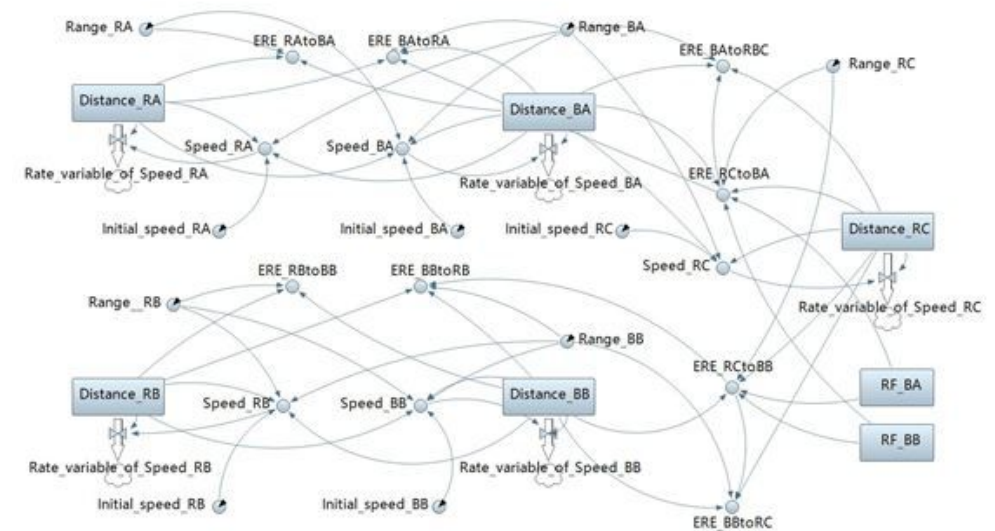

\section{Figure 3}

Stock-flow diagram as quantified by the rules of engagement of directly-aimed weapons RA: the main ground assault group of the red force; RB: the assist ground assault group of the red force; RC: the reserve ground assault group of the red force; BA: the left side defense combat groups of the blue force; BB: the right side defense combat groups of the blue force; Distance_RA: the distances to the target from a detachment of the red force; Distance_BA: the distances to the target from a detachment of the blue force; RF_BA: the remaining combat forces of the group BA of the blue force; RF_BB: the remaining combat forces of the group BB of the blue force; Speed_RA: the real-time speeds of the group RA of the red force; Speed_BA: the real-time speeds of the group BA of the blue force; Range_RA: the effective ranges of the group RA of the red force; Range_ BA: the effective ranges of the group BA of the blue force.

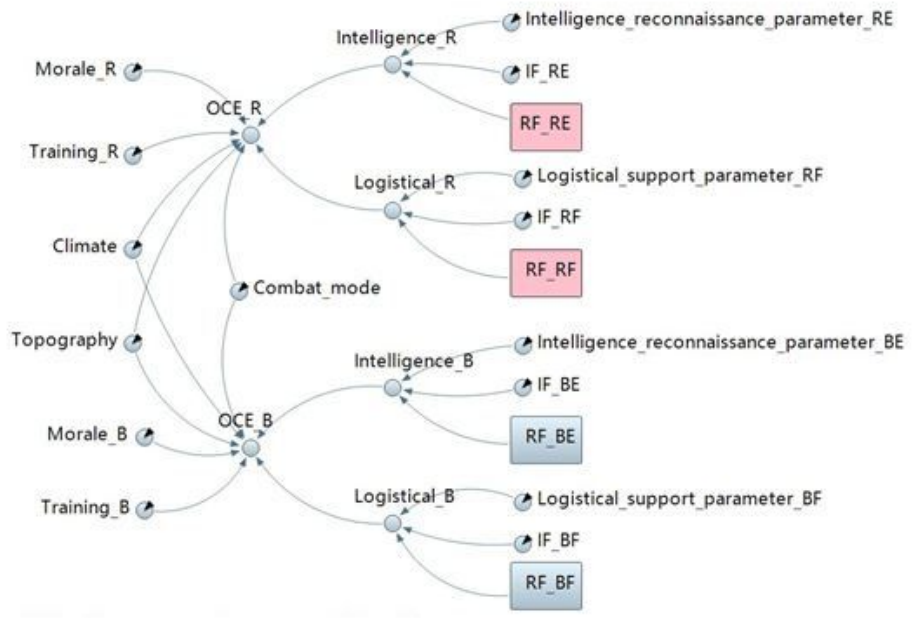

\section{Figure 4}

Stock-flow diagram as quantified by factors influencing the combat OCE_R: the combat influence factors of the red force; OCE_B: the combat influence factors of the blue force; Training_R, Morale_R, Combat_mode, Topography, and Climate: the quantified values of the influence factors for training, morale, combat style, natural terrain, environment, and climate for both the red and blue forces; Logistical_R , Intelligence_R: the quantified values of logistical support capabilities and information support operations capabilities; ' the current capability of the support forces and information operations forces of the red and blue sides 


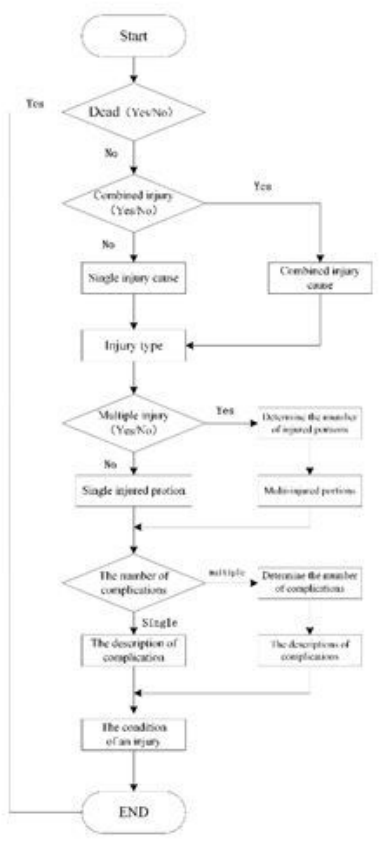

\section{Figure 5}

Flow chart of the logical relationship between combat injuries

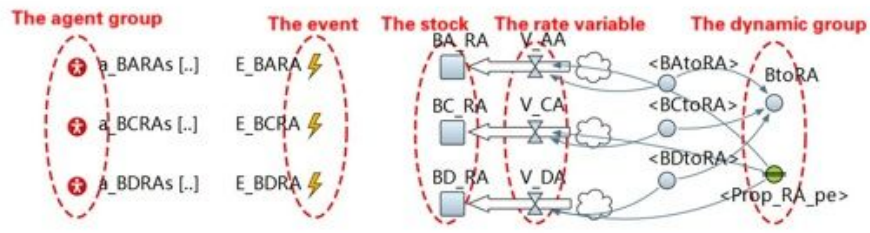

\footnotetext{
The agent group of a.BARAs/a BCRAs/a.BDRAs: group A in red force's injured individuals caused by ground troops/artillery/air force of the blue force.

The event of E_BARAE_BCRAE_BDRA: the functions used to convert the casualty stream to injured individuals.

The stock of BA_RABC_RABD_RA: the casualty stream of group $\mathrm{A}$ in the red force caused by ground troops/artillery/air force of the blue force.

The rate variable V_AAV_CAN_DA: the rate of casualties of group $A$ in the red force caused by ground troops/artillery/air force of the blue force.

The dynamic variable BAtoRA/BCtaRA/BDtoRA/BtoRA: the combat attrition equation for combat groups in the blue force

The dynamic variable Prop.BA. ane: the proportion of soldiers and equipment of group $A$ in the red force
}

\section{Figure 6}

Schematic diagram of intelligent agent (partial) a_BARAs, a_BCRAs, a_BDRAs: group A in red force's injured individuals caused by ground troops/artillery/air force of the blue force; E_BARA, E_BCRA, E_BDRA: the functions used to convert the casualty stream to injured individuals; BA_RA, BC_RA, BD_RA: the casualty stream of group $A$ in the red force caused by ground troops/artillery/air force of the blue force; V_AA, V_CA, V_DA: the rate of casualties of group $A$ in the red force caused by ground troops/artillery/air force of the blue force; BAtoRA, BCtoRA, BDtoRA, BtoRA: the combat attrition equation for combat groups in the blue force; Prop_RA_pe: the proportion of soldiers and equipment of group $A$ in the red force. 


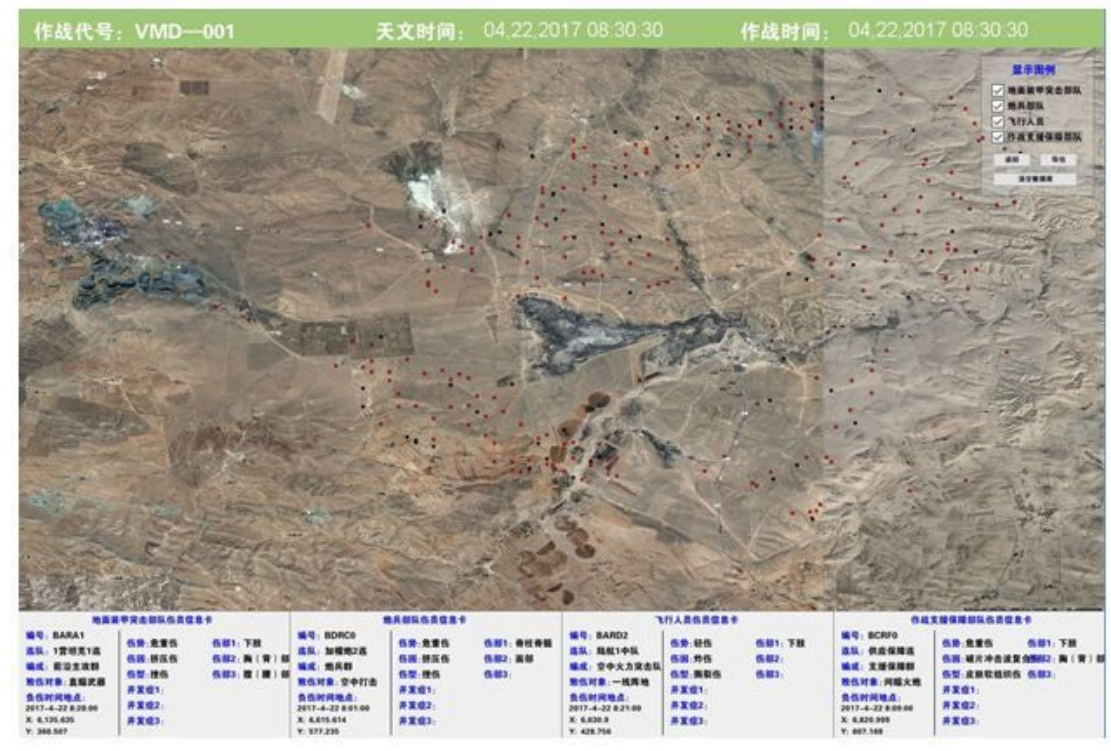

\section{Figure 7}

Combat attrition distribution interface of the simulation system

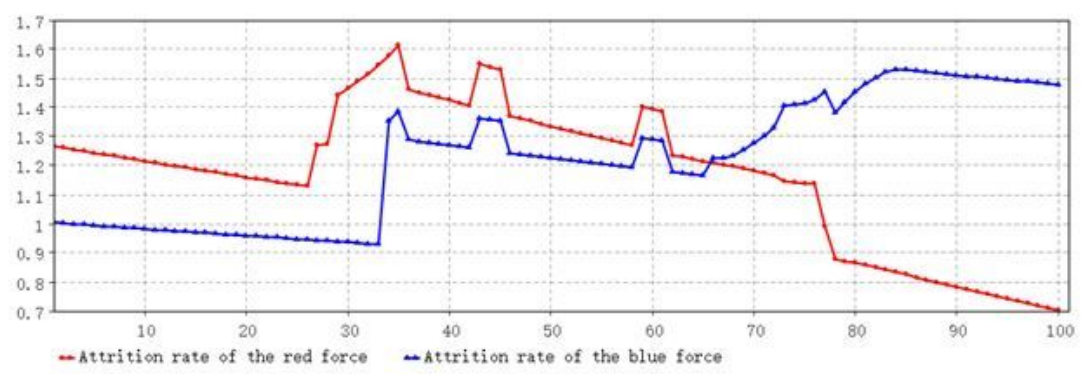

\section{Figure 8}

Graphs of total combat attrition and combat attrition rate (vertical axis: attrition; horizontal axis: minute) the red line: attrition of the red force; the blue line: attrition of the blue force; vertical axis: attrition; horizontal axis: minute.

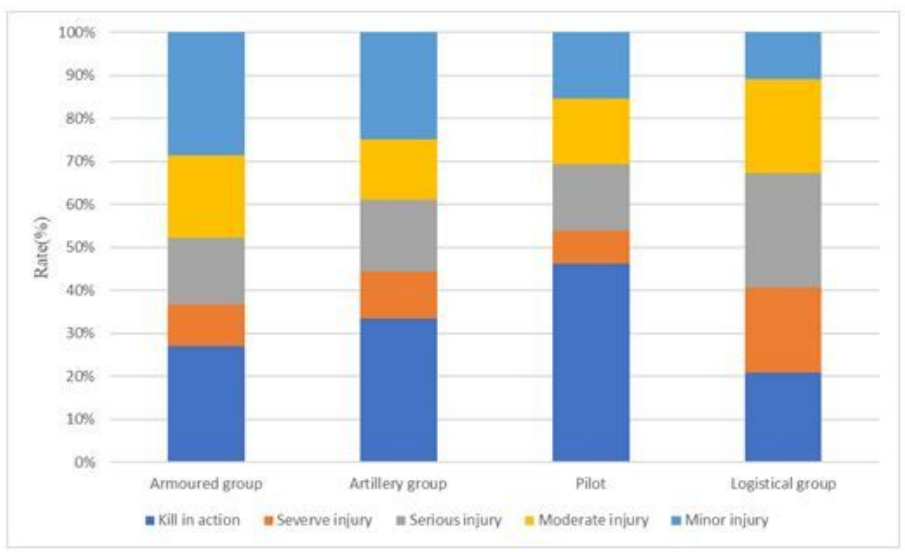

\section{Figure 9}

Distribution of injury level in the red force 


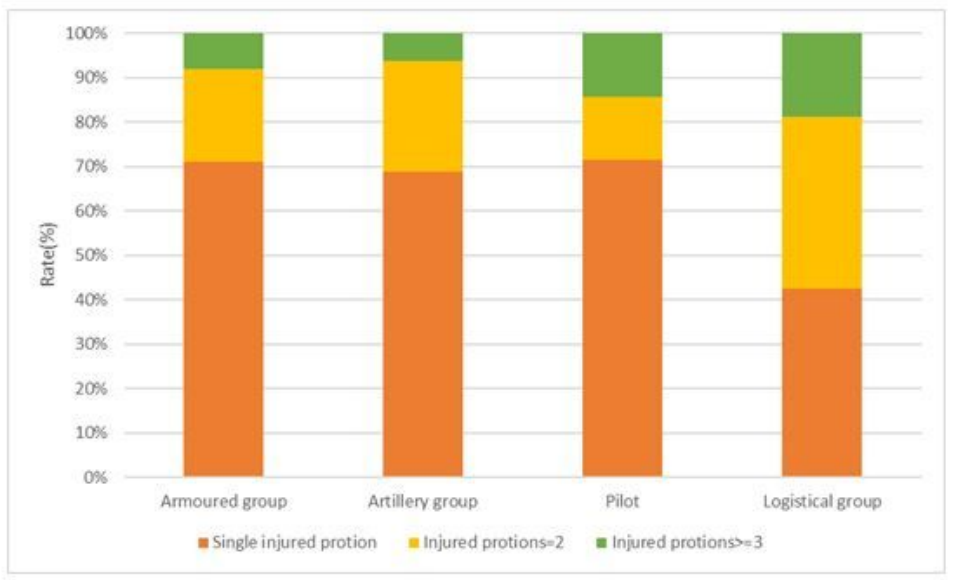

\section{Figure 10}

Distribution of the number of injury sites in combat groups of the red force 